\title{
THE ROLE OF CONVENIENCE, COMPATIBILITY AND MEDIA RICHNESS IN ACCEPTING MOBILE WEB IN MALAYSIA
}

\author{
L. Thaneshan ${ }^{1 *}$, Fadhilah Mat Yamin ${ }^{2}$, Siti Norezam Othman ${ }^{3}$ \\ 1 School of Technology Management, Universiti Utara Malaysia, Malaysia \\ Email: s95039@uum.edu.my \\ 2 School of Technology Management, Universiti Utara Malaysia, Malaysia \\ Email: fmy@uum.edu.my \\ 3 School of Technology Management, Universiti Utara Malaysia, Malaysia \\ Email: norezam@uum.edu.my \\ * Corresponding Author
}

\section{Article Info:}

\section{Article history:}

Received date: 02.06 .2020

Revised date: 13.06 .2020

Accepted date: 14.06 .2020

Published date: 15.06 .2020

\section{To cite this document:}

Thaneshan, L., Mat Yamin, F., \& Othman, S. N. (2020). The Role of Convenience, Compatibility and Media Richness in Accepting Mobile Web in Malaysia. Journal of Information System and Technology Management, 5 (17), 12-19.

DOI: $10.35631 /$ JISTM.517002.

\begin{abstract}
:
Our lifestyle has changed and keeps changing with emerging software and hardware technologies. In the same way, mobile devices are changing the way people accessing the Internet. More users have changed from using desktop computers to mobile devices. A mobile device such as smartphones and tablets are widely used devices in accessing the Internet all over the world. From an early investigation, it is found that although mobile devices are highly flexible, accessible, and convenient, their usage to access websites is still average. The objective of this study is to conceptualize the factors that drive users to access websites through mobile devices. This study presents the scenario and the current situation of mobile web usage among mobile device users. It further critically discusses the role of three constructs namely, convenience, compatibility, and media richness in explaining the user's intention to use the mobile web. The study adopts the Technology Acceptance Model (TAM) to understand what factors affect usage intention of the mobile web, an important topic for current and future research. The limitations lie in the depth of investigation where the empirical investigation should be conducted in future studies to prove the findings of this conceptual study. This study aims to explain the factors that will influence the intention to access mobile websites. Determining those factors will help web designers to develop mobile web pages that will be preferred by its users. Improving user's experience of accessing the web through mobile devices will enable web service providers to offer web services more effectively that will satisfy the needs of the users.
\end{abstract}

Keywords:

Mobile Web, Convenience, Compatibility, Media Richness 


\section{Introduction}

Mobile technology has become part of the everyday lives of billions of people all around the world (Goggin, 2012). Initially, mobile devices were designed with an emphasis on communication support for voice calling and text messaging, where they have limited capacity for data processing and least capacity in handling video contents (Male \& Pattinson, 2011). However, due to their unique characteristics and abilities, mobile devices are rapidly adopted for communication, thus made the developers and manufacturers of mobile devices to take the opportunity to innovate and expand their functional capabilities by incorporating other potential technologies such as audio, video and web browsing onto the mobile device platform without compromising the portability of these devices (Justiti \& Adhi Prasetyo, 2018; Male \& Pattinson, 2011). According to Tam, Santos, and Oliveira (2018), the market demand for mobile technology and communication services will grow at least five times faster than internal information technology (IT) organizations' capacity to deliver them.

Today, mobile devices such as smart phones, tablets and netbooks are widely used devices in accessing Internet all over the world (Johnson \& Seeling, 2013). Figure 1 shows the devices used to access Internet in Malaysia in 2018. It shows that Smartphones are the most used devices to access Internet with nine out of ten Internet users went online using the device (93.1\%). Second most used device to access Internet is Laptop or netbook with $44.2 \%$. While, the use of desktop computers to access internet is only $28.1 \%$. Twenty years back, the question on devices being used by Internet users to go online was almost irrelevant because desktop was the only mode of Internet access, even laptop was a luxury then(MCMC, 2018).

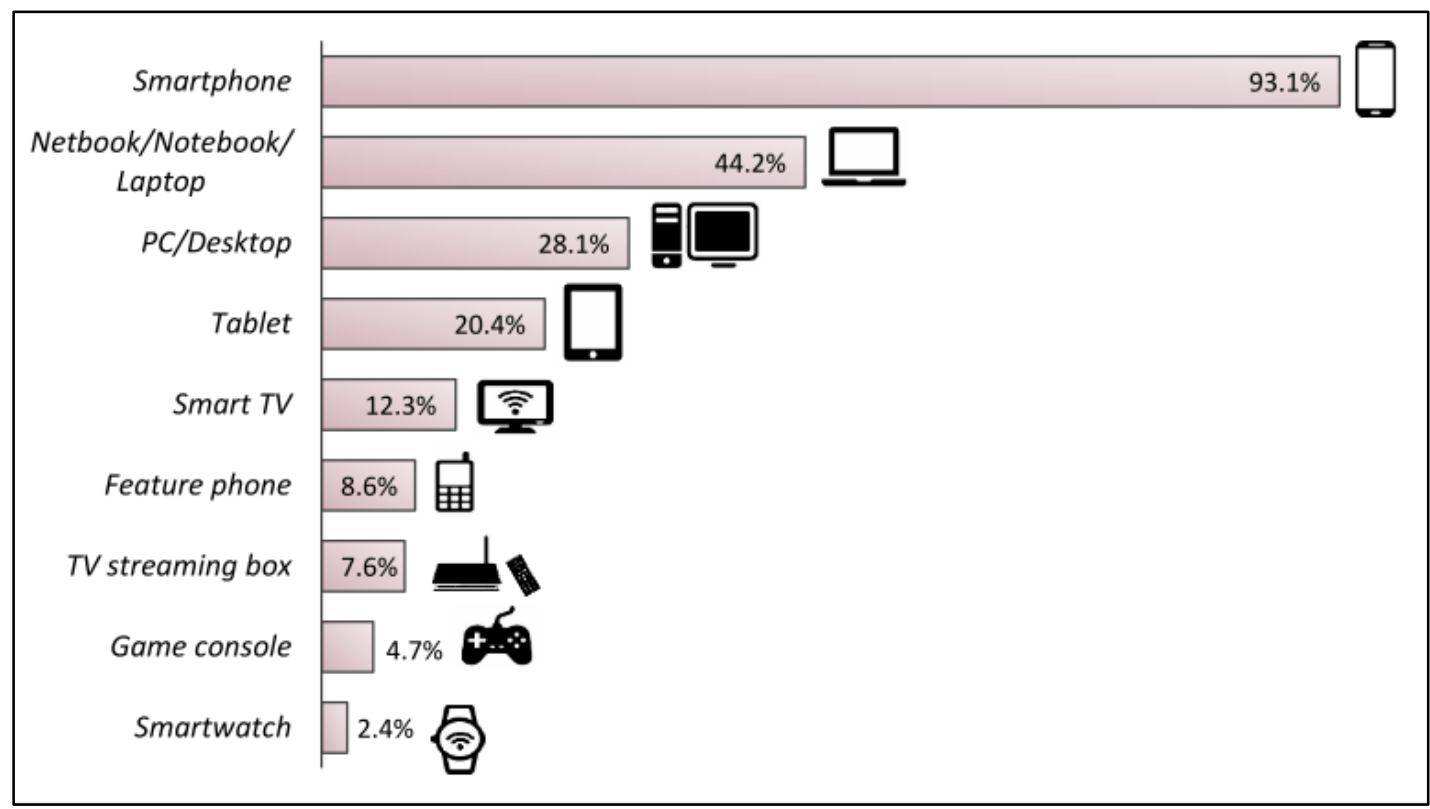

Figure 1: Devices Used to Access Internet in Malaysia in 2018

Source: Malaysian Communications and Multimedia Commission, 2018

However, although mobile devices are highly flexible, accessible and convenient, users are still facing great problems in rendering and navigating web contents on mobile devices (Kende, 2015). Most of the present websites are developed for desktop users only and they are not mobile friendly (Martin et al., 2012; Roudaki et al., 2015). They are poorly suited for mobile devices, making the web content look visually unpleasant and hard to navigate (Adipat et al., 2011; Fernandes et al., 2014). Most of this problems are rooting from the physical constrains 
of these devices, especially the smaller size of the screen, limited memory and interaction mechanism (Lu \& Rastrick, 2014; Zhang \& Lai, 2011).

In addition, majority of the past studies are focusing on appearance (physical interface) of the web page (Baturay \& Birtane, 2013; Chen et al., 2011) such as colour (Bonnardel et al., 2011), visual design and navigation design ( $L u$ \& Rastrick, 2014; Yu \& Kong, 2015). However, development of a mobile web page is not only about the look of the web page, where the developers need to consider several other factors (Henry, 2013). A good web page must aid users to find what they want and understand their exact location on the site. In overall, a web page should able to convince users to engage in the site (Chen et al., 2011).

Despite this, there are no any trustable models that explain the expectation of a user when he or she accesses a website through a mobile device (Al-Khalifa, 2014; Zhang \& Lai, 2011). So there is a gap exist to find how a mobile website should be designed from the view of users so that it will fulfil the expectation of the users. By identifying factors that influence intention towards accessing mobile websites, web developers are able to produce mobile web pages that will fulfil the expectation of its users.

\section{Review of Literature}

\section{Predictive Factor of Mobile Web Acceptance}

Research scholars have used several technology adoption theories in mobile related studies in order to determine drivers to adopt mobile services and applications. However, TAM is the most favoured theoretical model that been used to explain mobile web and mobile applications acceptance (Al-najjar, 2012). Moreover, scholars have modified, integrated, enriched, extended augmented, and decomposed this model so that it will be appropriately fit into the mobile acceptance studies. Several determinants have been explored in the past studies that influenced the adoption of web and mobile services. For example, Hanafizadeh, Behboudi, Koshksaray, and Tabar (2014) extended TAM with trust, perceived credibility, compatibility with life style, perceived cost, perceived risk and need for interaction.

Other researchers, Agrebi and Jallais (2015) integrated this model with satisfaction and perceived enjoyment in explaining usage intention of mobile devices to access shopping websites. Meanwhile, Lai and Chang (2011) extended TAM by including media richness, compatibility and convenience. In a research conducted by Verkasalo, López-Nicolás, MolinaCastillo, and Bouwman (2010), the authors argued that perceived enjoyment and perceived usefulness is strongly influencing intention to use applications across users and for non-users of mobile applications. In a study conducted in Malaysia, Wai (2015) examined perceived values, perceived control and trust and user experience as the determinants of individuals' intentions to use mobile coupon.

Convenience has become increasingly important to consumers, especially in the context of ICT adoption. Berry et al. (2002) stated that convenience is an important factor when it comes to saving consumers' time and effort where it is believed that time and effort are the main aspects that affects consumers' convenience. Still, small number of studies has been carried out to outline how convenience could be defined or examined in mobile service field (Okazaki \& Mendez, 2013).

While, compatibility is the degree to which an innovation is perceived as being consistent with the existing values, demands and past experiences of potential users (Rogers, 1983). Previous 
studies have proved that compatibility is an important factor that determines whether an individual is willing to adopt innovations (Al-Jabri, 2015; Hanafizadeh, Behboudi, Koshksaray, \& Tabar, 2014; Kleijnen et al., 2007; Lai \& Chang, 2011; Lin, 2011; Lin \& Lu, 2015; Moore \& Benbasat, 1991; Rogers, 1983). Internet users can access websites at any time by using mobile devices. Thus, it is expected that users are expecting mobile websites to be compatible with their daily lifestyle.

On the other hand, media richness is the ability of a communication medium to reproduce the information sent over it (Lai \& Chang, 2011). This study views mobile devices as a new way to access the Internet, particularly websites where the contents are sent through wireless networks. Hence, media richness is expected to influence the adoption of mobile web. Therefore, this research will develop and examine a theoretical model extended from TAM in mobile web adoption context, incorporating multiple constructs.

\section{Convenience}

Time is a valuable and limited resource. Consumers of a service are spending their time to attain the service and the time spent by those consumers while waiting to receive those services is an investment or a cost (Lai \& Chang, 2011). It plays a vital role in perception of users about convenience of a service. Time, unlike money, cannot be expanded and it is finite. Consumers will experience psychological suffering when they have to wait for something because there is a time loss. Taylor (1994) conducted a research to access the properties of the delay duration, effects of delay and degree to which time is filled, on affective and evaluative reactions to the delay. He found that that time spent for waiting negatively influences satisfaction of customer service.

According to Davis and Vollmann (1990), time spent for waiting will influence user's convenience. Seiders and Berry (1998) argues that the energy spent by consumers in waiting process is a cost and will affect consumer perceptions of convenience. Previous studies show that saving consumers' time and effort is important concept which will impact the perceived convenience of a service. Berry, Seiders, and Grewal (2002) stated that consumers' convenience is affected by time and effort. They claimed that benefit and post-benefit convenience, decision, transaction and access are the five dimensions of service convenience.

Convenience has become increasingly important to consumers, especially in ICT adoption context. Still, less studies has been carried out to outline how it could be defined or examined in mobile web (Okazaki \& Mendez, 2013). People are increasingly using mobile devices to access Internet and it has become a lifestyle to many of them. One of the important value added characteristic produced by mobile devices is convenience (Clarke, 2008; Sharma \& Gutiérrez, 2010). Although mobile devices are considered to be better in term of convenience compared to its desktop counterpart, mobile web is taking longer time to load and users requires longer time to view web pages due to unique constraints of mobile devices (Fernandes et al., 2014; Henry, 2013). Furthermore, most of the existing websites are designed and optimized for desktop users which make them poorly suited for mobile handheld devices (Adipat et al., 2011). In contrast, users are expecting the web pages to be loaded more quickly so that they can minimize the time spent for waiting (Lai \& Chang, 2011). In overall, perceptions of convenience to use mobile websites will be improved when the time spent for waiting is minimized. This in turn will affect their attitude towards using mobile web. 


\section{Compatibility}

Mobile devices are one of the innovative products that have overturned traditional desktop computers and expand and transform existing product functions. In order to meet consumer demands and market needs, mobile device producers are keep improving their mobile devices and offering functions that are not previously available. They keep focusing on producing devices which are compatible with user's prior experience. According to Rogers (1983), one of the main determinant that influences an individual's willingness to accept a specific technology is compatibility. He defined compatibility as "the degree to which an innovation is perceived as being consistent with the existing values, past experiences, and needs of potential adopters" (p. 15). Moore and Benbasat (1991) identified compatibility as one of the important characteristics of using an innovation.

Lai and Chang (2011) explored the determinants that drive users to use e-book readers for reading. They found that compatibility is positively influencing the technology acceptance. Recently, Lin and Lu (2015) proofed that compatibility is having significant impact on the user acceptance of mobile services. They conducted a study to examine the acceptance of mobile social networking sites. While, Hanafizadeh et al., (2014) found that compatibility with life style and needs is the most effective factor that contribute to the mobile banking adoption. Internet users are no longer limited to use traditional desktop computers to access websites. They can use the functions provided on the websites at any time by using mobile devices. Therefore, it is expected that users will have a favourable attitude to access websites through mobile devices when they believe that mobile websites are compatible with their way of living.

\section{Media Richness}

The concept of media richness is developed by Daft and Lengel (1984) in their Media Richness Theory. They defined media richness as the ability to convey information and enable users to communicate and exchange understanding. Newberry (2001) argued that there are various media types from 'richest' to 'leanest'. According to them, richest medium among all the communication mediums is face to face medium, while threaded discussion is the leanest. According to his argument, richer media such as face to face communication and video conferencing contain more social, non-verbal cues and it has greater feedback while less rich media such as asynchronous audio and threaded discussion have less capacity to facilitate communication.

There are several studies been conducted utilizing Media Richness Theory and their findings shows support when the theory is applied to traditional mediums including face to face communication and other written media such as fax, letter and memos (Russ et al., 1990). In contrast, inconsistent results are found in some studies when Media Richness Theory is applied to modern mediums including video, audio, e-mail, website and other computer mediated communications (Dennis \& Kinney, 2014; Suh, 1999). Coyle and Thorson (2001) conducted a study to examine vividness and interactivity of commercial web pages. They found that websites that has animation and audio are positively influencing user's attitude toward websites. This study views mobile devices as a new way to access the Internet, particularly websites where the web contents are provided through wireless networks. Hence, media richness is expected to influence users' attitude towards accessing mobile web.

\section{Discussion and Conclusion}

Although Internet penetration and mobile device usage has seen a dramatic increase within a short period of, mobile device usage to access website is still average among Malaysians. This projects that there is an issue in mobile web usage. Mobile device users are facing great 
problems in rendering and navigating web contents on mobile devices which eventually makes the mobile web not user friendly. This problem makes the web developers fail to adequately satisfy the needs of the users. In order to present the content of web on mobile device in a way that will satisfy the needs of users and will help them to find information of interest more effectively, web developers should be focusing on convenience, compatibility and media richness of the mobile web. Users are expecting the web pages to be loaded more quickly, compatible with their way of living and providing richer content.

\section{References}

Adipat, B., Zhang, D., \& Zhou, L. (2011). The Effects of Tree-View Based Presentation Adaptation on Mobile Web Browsing. MIS Quarterly, 35(1), 99-122.

Agrebi, S., \& Jallais, J. (2015). Explain the intention to use smartphones for mobile shopping. Journal of Retailing and Consumer Services, 22, 16-23. https://doi.org/10.1016/j.jretconser.2014.09.003

Al-Khalifa, H. S. (2014). A framework for evaluating university mobile websites. Online Information Review, 38(2), 166-185. https://doi.org/10.1108/OIR-12-2012-0231

Al-najjar, G. M. (2012). Mobile Information Systems: An Empirical Analysis of the Determinants of Mobile Commerce Acceptance in Jordan. Universiti Utara Malaysia.

Baturay, M. H., \& Birtane, M. (2013). Responsive Web Design: A New Type of Design for Web-based Instructional Content. Procedia - Social and Behavioral Sciences, 106, 2275-2279. https://doi.org/10.1016/j.sbspro.2013.12.259

Berry, L. L., Seiders, K., \& Grewal, D. (2002). Understanding service convenience. Journal of Marketing, 66(3), 1-17.

Bonnardel, N., Piolat, A., \& Le Bigot, L. (2011). The impact of colour on Website appeal and users' cognitive processes. Displays, 32(2), 69-80. https://doi.org/10.1016/j.displa.2010.12.002

Chen, J. V., Lin, C., Yen, D. C., \& Linn, K.-P. (2011). The interaction effects of familiarity, breadth and media usage on web browsing experience. Computers in Human Behavior, 27(6), 2141-2152. https://doi.org/10.1016/j.chb.2011.06.008

Clarke, I. (2008). Emerging Value Propositions for M-commerce. Journal of Business Strategies, 25(2), 41-57. http://search.ebscohost.com/login.aspx?direct=true\&profile=ehost\&scope=site\&autht ype $=$ crawler \&jrnl $=08872058 \& A N=36541869 \& h=x l j d Y w M f e H A f O Q j o u n U G t Y h G 2$ 2YVlhWxP2xW6zINTw/eC0xmI9n2Gria/wi/xyN2vecvs2vsEboJdk9iKT5Sfg==\&crl $=\mathrm{c}$

Coyle, J. R., \& Thorson, E. (2001). The Effects of Progressive Levels of Interactivity and Vividness in Web Marketing Sites. Journal of Advertising, 30(3), 65-77. https://doi.org/10.1080/00913367.2001.10673646

Daft, R. L., \& Lengel, R. H. (1984). Information Richness: A New Approach to Managerial Behaviour and Organizational Design. Research in Organizational Behaviour, 6, 191233.

Davis, M. M., \& Vollmann, T. E. (1990). A Framework for Relating Waiting Time and CustomerSatisfaction in a Service Operation. Journal of Services Marketing, 4(1), 6169. https://doi.org/10.1108/EUM0000000002506

Dennis, A. R., \& Kinney, S. T. (2014). Testing Media Richness Theory in the New Media: The Effects of Cues, Feedback, and Task Equivocality. Information Systems Research, 9(3), 256-274.

Fernandes, N., Rodrigues, A., Duarte, C., Hijon-Neira, R., \& Carrico, L. (2014). Web Accessibility of Mobile and Desktop Representations. Proceedings of BCS HCI, 1-8.

Goggin, G. (2012). Cell phone culture: Mobile technology in everyday life. Routledge. 
Hanafizadeh, P., Behboudi, M., Koshksaray, A. A., \& Tabar, M. J. S. (2014). Mobile-banking adoption by Iranian bank clients. Telematics and Informatics, 31(1), 62-78. https://doi.org/10.1016/j.tele.2012.11.001

Henry, A. (2013). Optimize Your Website for the Mobile User. Rural Telecom, 32(3), 18-22.

Johnson, T., \& Seeling, P. (2013). Desktop and Mobile Web Page Comparison: Characteristics, Trends, and Implications. Communications Magazine, IEEE, 1-14. http://arxiv.org/abs/1309.1792

Justiti, N. D. N., \& Adhi Prasetyo, S. T. (2018). The Analysis about Behavior Intention of Customers on Using Smartphone. International Journal of Scientific and Research Publications (IJSRP), 8(3), 354-360. https://doi.org/10.29322/IJSRP.8.3.2018.p7551

Kende, M. (2015). Global Internet Report 2015. Mobile evolution and development of the Internet.

Lai, J.-Y., \& Chang, C.-Y. (2011). User attitudes toward dedicated e-book readers for reading: The effects of convenience, compatibility and media richness. In Online Information Review (Vol. 35, Issue 4, pp. 558-580). https://doi.org/10.1108/14684521111161936

Lin, K., \& Lu, H.-P. (2015). Predicting mobile social network acceptance based on mobile value and social influence. Internet Research, 25(1), 107-130. https://doi.org/10.1108/IntR-01-2014-0018

Lu, Y., \& Rastrick, K. (2014). Impacts of Website Design on the Adoption Intention of Mobile Commerce: Gender as a Moderator. New Zealand Journal of Applied Business Research, 12(2), 51-69.

Male, G., \& Pattinson, C. (2011). Enhancing the quality of e-learning through mobile technology: A socio-cultural and technology perspective towards quality e-learning applications. Campus-Wide Information Systems, 28(5), 331-344. https://doi.org/10.1108/10650741111181607

Martin, F., Pastore, R., \& Snider, J. (2012). Developing Mobile Based Instruction. TechTrends, 56(5), 46-51. https://doi.org/10.1007/s11528-012-0598-9

MCMC. (2018). Internet users survey 2018: Statistical brief number twenty-three. Internet Users Survey 2018, 1-39. https://www.mcmc.gov.my/skmmgovmy/media/General/pdf/Internet-Users-Survey2018.pdf

Moore, G. C., \& Benbasat, I. (1991). Development of an instrument to measure the perceptions of adopting an information technology innovation. Information Systems Research, 2(3), $192-222$.

Newberry, B. (2001). Raising Student Social Presence in Online Classes. World Conference on the $W W W$ and Internet Proceedings, Orlando, F, 7. http://eric.ed.gov/ERICWebPortal/recordDetail?accno=ED466611

Okazaki, S., \& Mendez, F. (2013). Exploring convenience in mobile commerce: Moderating effects of gender. Computers in Human Behavior, 29(3), 1234-1242. https://doi.org/10.1016/j.chb.2012.10.019019

Rogers, E. M. (1983). Diffusion of Innovtions. In Diffusion of innovations (Third edit). The free press. http://hollis.harvard.edu/?itemid=\%7Clibrary/m/aleph\%7C006256656

Roudaki, A., Kong, J., \& Yu, N. (2015). A classification of web browsing on mobile devices. Journal of Visual Languages \& Computing, 26, 82-98. https://doi.org/10.1016/j.jvlc.2014.11.010

Russ, G. S., Daft, R. L., \& Lengel, R. H. (1990). Media selection and managerial characteristics in organizational communications. Management Communication Quarterly, 4(3), 151175.

Seiders, K., \& Berry, L. L. (1998). Service fairness: What it is and why it matters. Academy of Management Executive, 12(2), 8-20. https://doi.org/10.5465/AME.1998.650513 
Sharma, S., \& Gutiérrez, J. A. (2010). An evaluation framework for viable business models for m-commerce in the information technology sector. Electronic Markets, 20, 33-52. https://doi.org/10.1007/s12525-010-0028-9

Suh, K. S. (1999). Impact of communication medium on task performance and satisfaction: an examination of media-richness theory. Information \& Management, 35(5), 295-312. https://doi.org/10.1016/S0378-7206(98)00097-4

Tam, C., Santos, D., \& Oliveira, T. (2018). Exploring the influential factors of continuance intention to use mobile Apps: Extending the expectation confirmation model. Information Systems Frontiers, 2018, 1-27. https://doi.org/10.1007/s10796-018-98645

Taylor, S. (1994). Waiting for service: The relationship between delays and evaluations of service. Journal of Marketing, 58(2), 56-69. https://doi.org/10.2307/1252269

Verkasalo, H., López-Nicolás, C., Molina-Castillo, F. J., \& Bouwman, H. (2010). Analysis of users and non-users of smartphone applications. Telematics and Informatics, 27(3), 242-255. https://doi.org/10.1016/j.tele.2009.11.001

Wai, C. K. (2015). Intention and Adoption of Mobile Coupon among Mobile Phone Users in Klang Valley. Universiti Utara Malaysia.

Yu, N., \& Kong, J. (2015). User experience with web browsing on small screens: Experimental investigations of mobile-page interface design and homepage design for news websites. Information Sciences. https://doi.org/10.1016/j.ins.2015.06.004

Zhang, D., \& Lai, J. (2011). Can Convenience and Effectiveness Converge in Mobile Web? A Critique of the State-of-the-Art Adaptation Techniques for Web Navigation on Mobile Handheld Devices. In International Journal of Human-Computer Interaction (Vol. 27, Issue 12, pp. 1133-1160). https://doi.org/10.1080/10447318.2011.559876 